\title{
The metal Rhodium does not have allotropes
}

Zoltan $\underline{\text { Szucs }}^{1}$, Danie $\underline{\text { Moolman }}^{2}$, Sabine $\underline{\text { Verryn }}^{3}$, Jan Rijn $\underline{\text { Zeevaart }}^{1,4, *}$

\author{
${ }^{1}$ Necsa, Radiochemistry, Pretoria, South Africa \\ ${ }^{2}$ Necsa, Delta-F, Pretoria, South Africa \\ ${ }^{3}$ University of Pretoria, Dept. Geology, X-Ray Analytical Facility, Pretoria, South \\ Africa \\ ${ }^{4}$ CARST, North West University - Mafikeng Campus, South Africa
}

* Corresponding author: PO Box 582, Pretoria 0001, South Africa, E-mail: zeevaart@necsa.co.za, phone: +27123055786, fax: +27123055944

Keywords: allotropy, Rhodium, Gmelins Handbuch, XRD, differential thermal analysis 


\begin{abstract}
Research into a new method for separating Palladium from Rhodium, based on radiochemical principles, necessitated a re-investigation of the Gmelins Handbuch data indicating that Rh has allotropes. Two independent and different methods were used, which both yielded the same results; i.e. that no allotropy can be found. Non-ambient temperature X-ray diffraction (HT-XRD) did not show any difference in the diffractograms due to phase transformation of $\mathrm{Rh}$-metal at elevated temperatures. Differential Thermal Analysis (DTA) confirmed the HT-XRD result in the temperature range of $1000-1400{ }^{\circ} \mathrm{C}$. In conclusion, the absence of allotropy of the metal Rhodium was proven.
\end{abstract}

\title{
INTRODUCTION
}

The ${ }^{103} \mathrm{Pd}$ radioisotope $\left(\mathrm{T}_{1 / 2}=16.96 \mathrm{~d}\right)$ is a therapeutic radioisotope extensively exploited in brachytheraphy to cure prostate cancer. Alternatively, it could be the potential mother isotope of the in vivo ${ }^{103} \mathrm{Pd} /{ }^{103 \mathrm{~m}} \mathrm{Rh}$ generator ${ }^{1}$, which could open new possibilities for its application in radiopharmacy. Although carrier- added ${ }^{103} \mathrm{Pd}$ (produced extensively in a number of ways) can be used for brachytherapy, the irradiation of Rh by a cyclotron is the only way for the production of carrierfree ${ }^{103} \mathrm{Pd}$, which is essential for the production of radiopharmaceuticals used in nuclear medicine. However, the widely-used separation of the ${ }^{103} \mathrm{Pd}$ from the target material and recovery of the Rh by "wet" chemistry, a very complicated and expensive procedure, using harmful chemicals is labour intensive, yields a low percentage of $\mathrm{Rh}$ recovery and produces radioactive waste.

An alternative technology would be based on the "thermo-diffusion" method ${ }^{2}$. The principle of this technique is the following: The "contaminating" radioactive new element produced can diffuse out from the deformed metal crystals and will enrich on the surface of the target during the heating of the irradiated metal. This process is more characteristic if the irradiating beam particles are heavier (deuteron, ${ }^{3} \mathrm{He}, \alpha$ ) and the heated metal has a change in its crystalloid form, i.e. it has allotropes. During the phase transfer, the diffusion coefficients of the trace element can increase with a magnitude of 
3-6 ${ }^{3}$. The re-crystallisation in the new crystal form excludes the trace atoms from the new crystalline form. Therefore, the trace element is forced out from the new crystal and able to diffuse out on the surface of the material. After that, the enriched isotopes can easily be evaporated from or chemical removed from the surface and be collected separately.

The current version of Gmelins Handbuch ${ }^{4}$ still includes the 73 years old literature that reported different allotrope forms of the metal Rhodium, viz. the alpha form, which is the primitive cubic crystal that transforms to the beta form, which is a face-centred cubic lattice, between 1000 and $1400{ }^{\circ} \mathrm{C}$. On the basis of this information, a systematic study of the parameters of the expected new separation method via thermo-diffusion was carried out. The series of unsuccessful experiments ${ }^{5}$ necessitated that the abovementioned allotropy be investigated.

It could also be argued that characteristic phenomena of material could be ascribed to the intrinsic properties of the crystalline structure of the material. Phase-transition temperature should coincide with anomalies in measured data for relevant properties as a function of temperature. Properties such as electrical conductivity, specific heat, thermal conductivity, diffusivity, and thermal EMF do not show any deviation or anomalies in the temperature range under discussion ${ }^{6,7,8,9}$.

It is known from the literature that the structure of Rhodium has been the subject of some investigations towards explaining some mechanical properties of the metal. A possible transformation was investigated ${ }^{\mathbf{1 0 , 1 1}}$ to reveal possible influences on the phenomenon that Rhodium is more difficult to work with than other metals of similar crystallographic structure, such as copper, silver, gold, platinum and palladium. The allotropy of Rhodium was also not indicated in other data relating to values of thermal expansion coefficients and length change measurements that are used to calculate the variations with temperature of lattice parameters, interatomic distances, atomic and molar volumes and density ${ }^{12}$.

X-ray diffraction is a commonly used method for the determination of the crystalline structure of solid samples. Scans can also be obtained at non-ambient temperatures (HT- 
$\mathrm{XRD}$ ). It is therefore a useful tool to investigate the allotrope forms of metals (e.g. Rhodium) in the above-mentioned temperature range of 1000 and $1400{ }^{\circ} \mathrm{C}$.

Differential thermal analysis (DTA) is another widely used thermal analysis technique for identification and fingerprinting in determination of phase diagrams, heat change measurements and other temperature related changes. Temperature changes in the sample are due to endothermic or exothermic transitions or reactions which can be a result of those caused by e.g. phase changes or crystalline structure inversions or destruction of crystalline lattice structures ${ }^{13,14}$.

In this paper, we report the experimental results of these two independent methods that prove the absence of the allotropy of Rhodium in this temperature range.

Table 1: Values of $\mathrm{N}=\mathrm{h} 2+\mathrm{k} 2+\mathrm{l} 2$ for which Bragg reflections are possible in $\mathrm{P}$ and $\mathrm{F}$ cubic lattices

\begin{tabular}{|c|c|c|c|}
\hline $\mathrm{P}(\mathrm{Sc})$ & $\mathrm{F}(\mathrm{fcc})$ & $\mathrm{hkl}$ & $\mathrm{d}(\AA)$ measured for $\mathrm{Rh}$ \\
\hline 1 & - & 100 & - \\
\hline 2 & - & 110 & 2.198 \\
\hline 3 & 3 & 111 & 1.904 \\
\hline 4 & 4 & 200 & - \\
\hline 5 & - & 210 & - \\
\hline 6 & - & 211 & 1.346 \\
\hline- & - & - & - \\
\hline 8 & 8 & 220 & - \\
\hline 9 & - & 300,221 & 1.147 \\
\hline 10 & 11 & 310 & 1.097 \\
\hline 11 & 12 & 222 & - \\
\hline 12 & & & \\
\hline
\end{tabular}




\section{RESULTS AND DISCUSSION}

The reported phase-transfer from the primitive $\alpha$-cubic lattice of $\mathrm{Rh}$ to the $\beta$-cubic facecentred form should have resulted in a difference between the several HT-XRD spectra as is summarised in Error! Reference source not found.. However, the spectra taken from room temperature up to $1500{ }^{\circ} \mathrm{C}$ show only additional peaks produced by $\mathrm{Pt}$ from the heating filament of the Anton Paar ${ }^{\mathrm{TM}}$ (HTK16) high temperature chamber attached to the goniometer of the $\mathrm{X}$-ray diffractometer, and identical peaks for $\mathrm{Rh}$ in all spectra as seen at $25{ }^{\circ} \mathrm{C}$. The measurement was repeated with fine metal powder of Rh to ensure random orientation of the material and to detect all possible reflections (see Error! Reference source not found., Error! Reference source not found. and Error! Reference source not found.). These results show clearly that no allotropy was found.

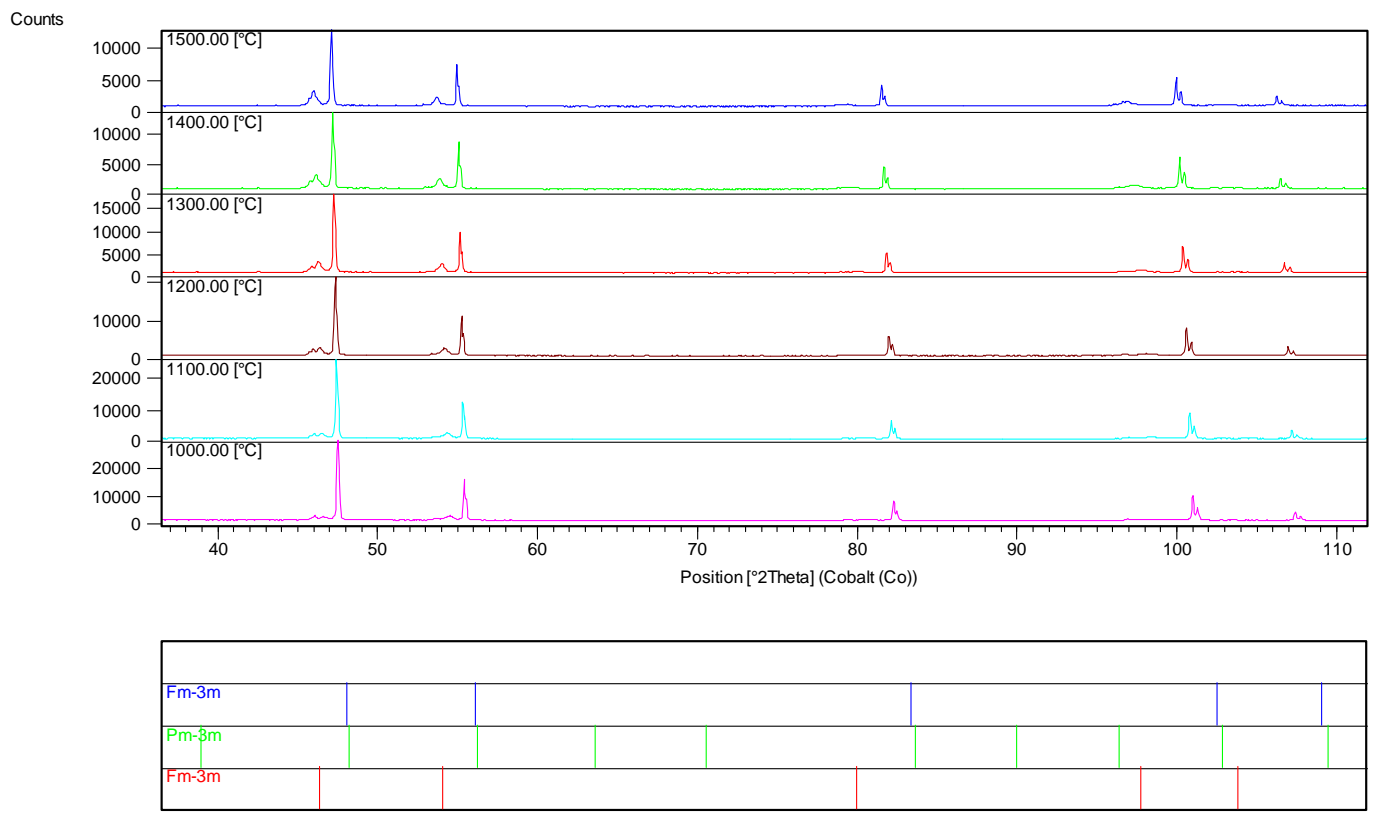

Figure 1: $\mathrm{XRD}$ traces of $\mathrm{Rh}$ powder between $1000^{\circ} \mathrm{C}$ and $1500{ }^{\circ} \mathrm{C}$ scanned in $\mathrm{Ar}$ atmosphere with peak positions of the primitive - cubic (Pm-3m) and facecentred cubic (Fm-3m) as well as the positions for Pt (bottom Fm-3m)

DTA results are presented in the temperature range 1000 to $1400^{\circ} \mathrm{C}$. Typical heating and cooling curves are presented in Figure 4 and Figure 5 for Rhodium foil and granulates respectively, with no thermal events due to allotropic transformations present. 
Gold was included as a reference and the $0.7^{\circ} \mathrm{C} / \mathrm{mg}$ high peak is clearly visible, while only a gradual drift is observed for Rhodium during heating and cooling with an overall magnitude far less than this.

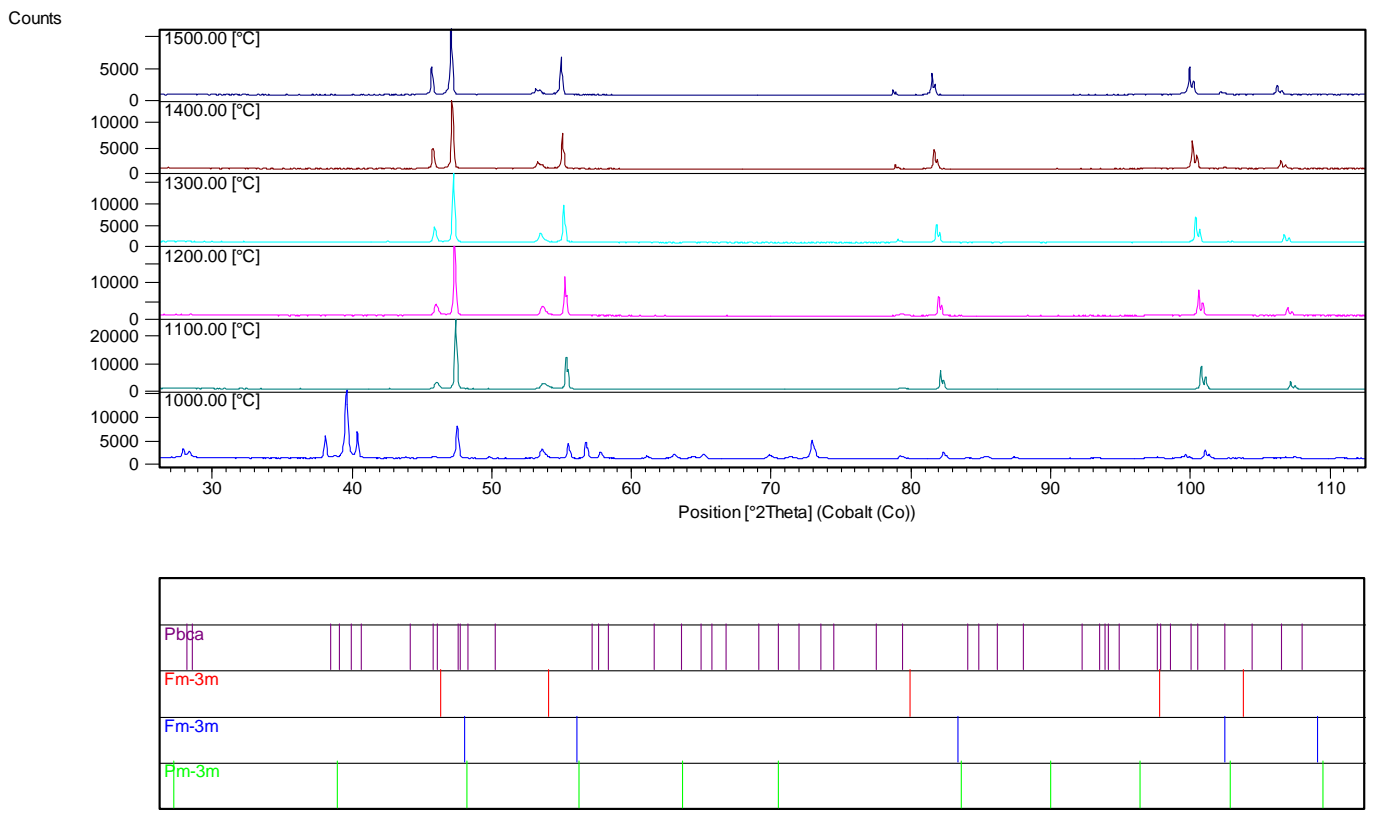

Figure 2: XRD traces of Rh powder between $1000^{\circ} \mathrm{C}$ and $1500^{\circ} \mathrm{C}$ scanned in $\mathrm{N} 2$ with peak positions of the primitive - cubic (Pm-3m) and face-centred cubic (Fm3m), Rh2O3 (Pbca) as well as the positions for Pt (under Pbca).

The amorphous mixture used as samples recorded in the old paper ${ }^{4}$ may be the reason for the incorrect data found in the past.

\section{CONCLUSION}

Two different, independent analytical methods yielded the same result on the allotropy of $\mathrm{Rh}$, i.e. that the metal $\mathrm{Rh}$ remains in only one crystal form and that no evidence of any other allotrope from room temperature up to $1400{ }^{\circ} \mathrm{C}$ was found. The HT-XRD measured the structure of the Rh-powder sample to detect different types of the crystalloid form should they form during the temperature change. It seems that the dominant lattice is the cubic-face centred lattice, i.e. the $\beta$-form. The DTA method monitored the expected energy change in the sample during the phase-transfer. 


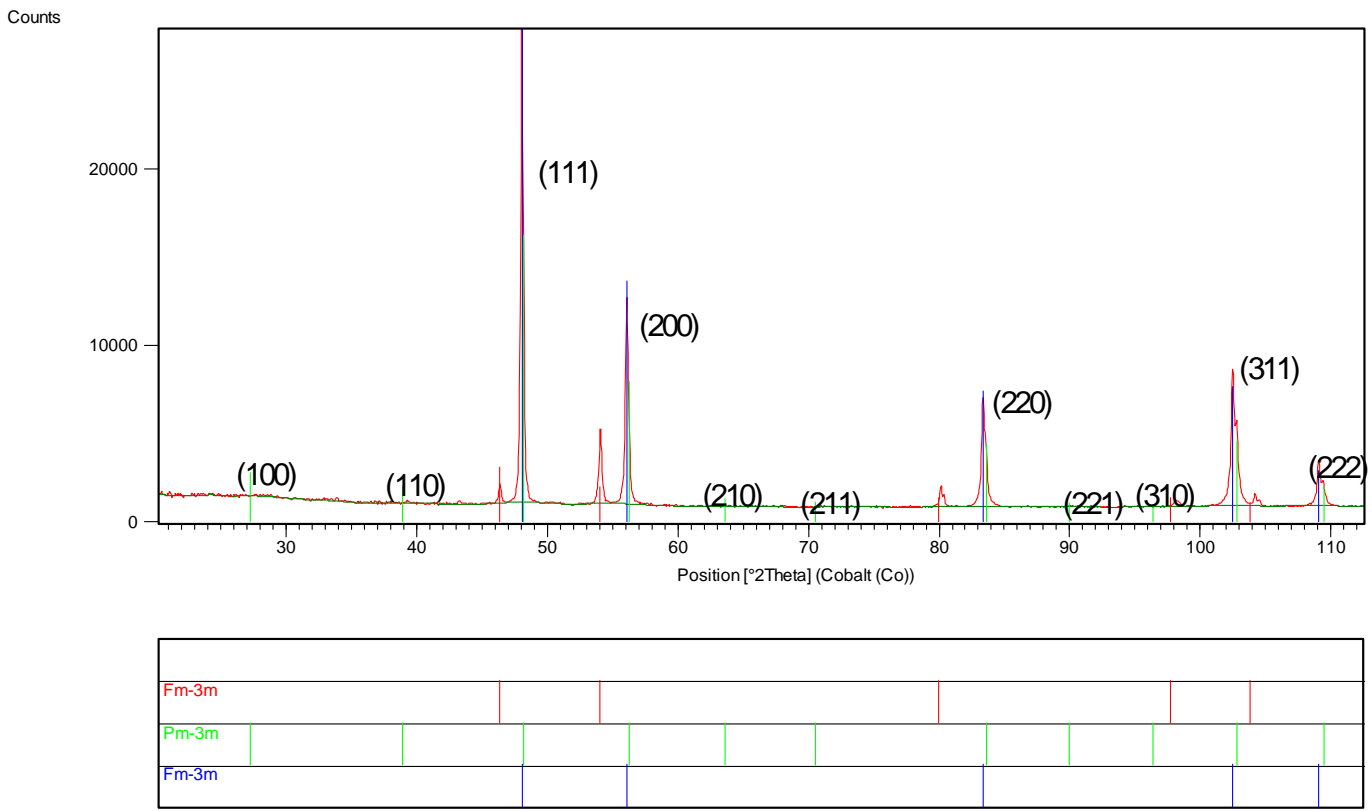

Figure 3: $\mathrm{XRD}$ traces of $\mathrm{Rh}$ powder at $25^{\circ} \mathrm{C}$ with peak positions of the primitive - cubic $(\mathrm{Pm}-3 \mathrm{~m})$ and face-centred cubic $(\mathrm{Fm}-3 \mathrm{~m})$ as well as the positions for $\mathrm{Pt}$ (bottom Fm-3m)

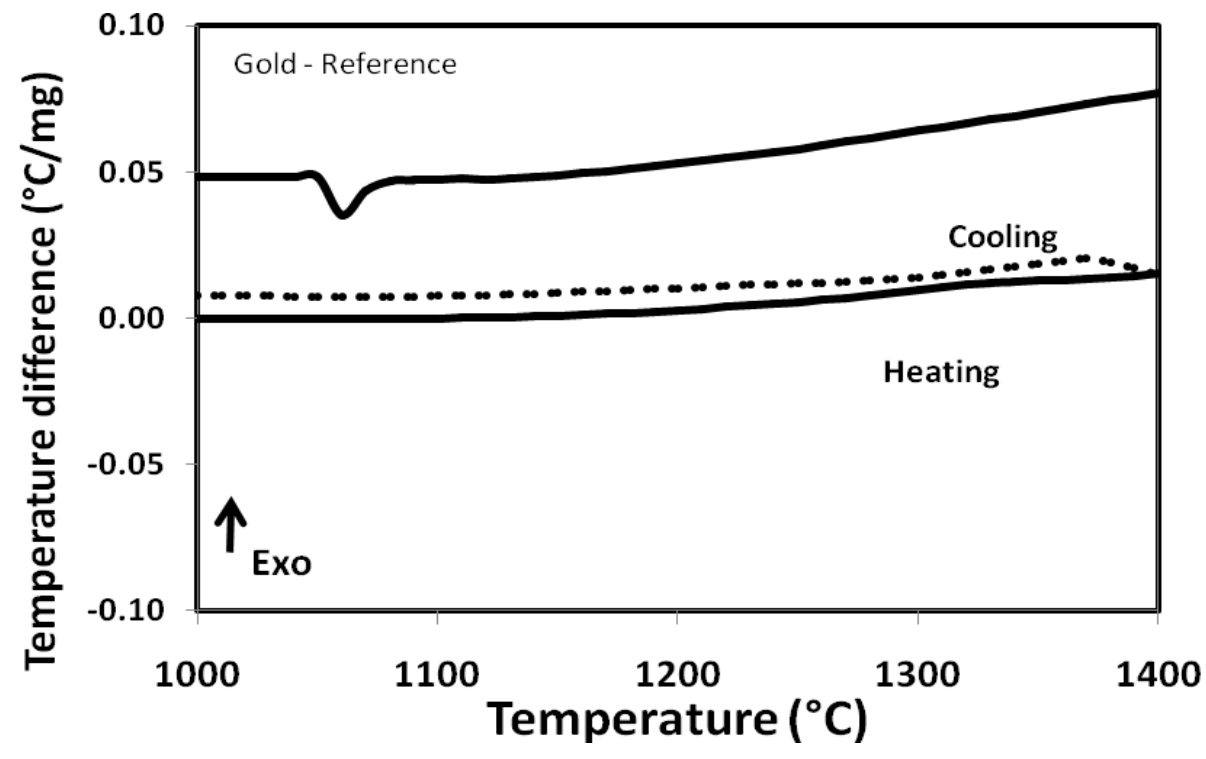

Figure 4: DTA curves of Rhodium foil (__ Heating, (.........) Cooling 


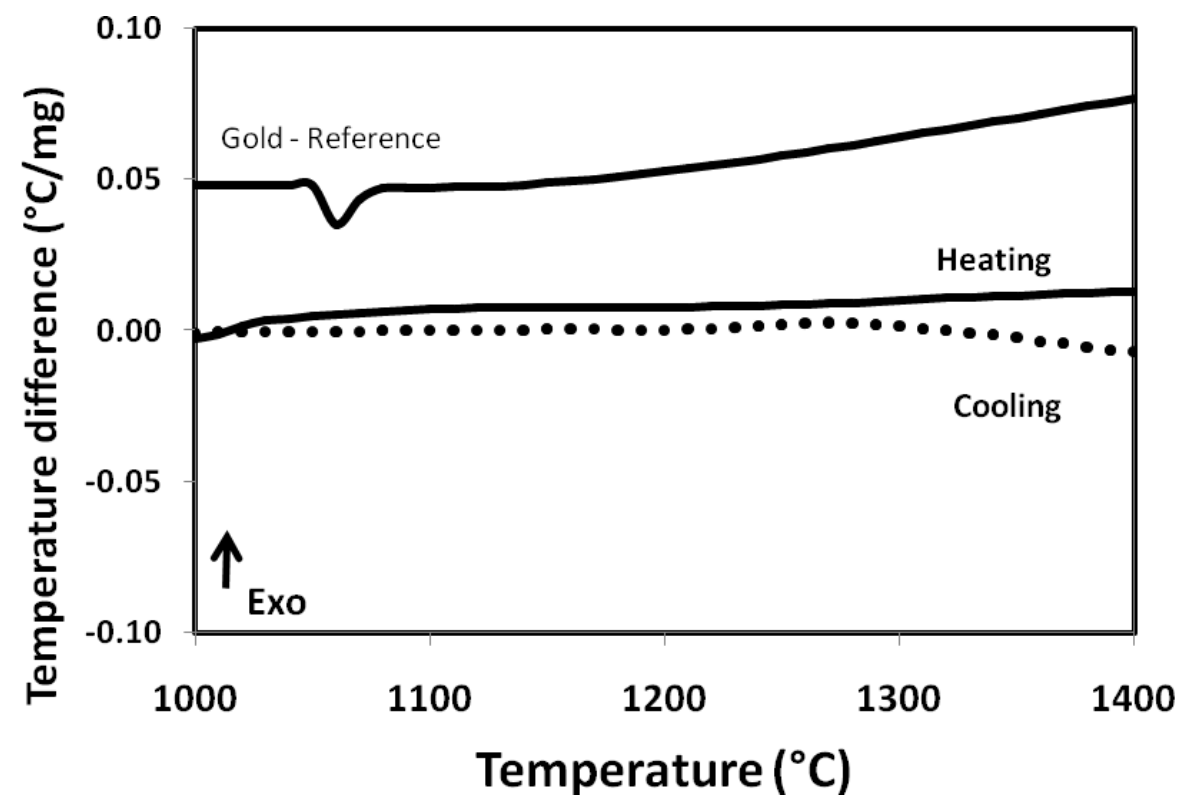

Figure 5: DTA curves of Rhodium granulate (__ Heating , (.....) Cooling.

\section{EXPERIMENTAL}

The rhodium foil $(50$ and $25 \mu \mathrm{m})$ and granulate $(20 \mathrm{mesh})$ was obtained from Sigma-Aldrich Chemie GmbH (Germany, www.sial.com). The certificate of the quality indicates the concentration level of the contaminating elements to be less than $50 \mathrm{ppm}$, except for Indium, which is $100 \mathrm{ppm}$.

The $\mathrm{Rh}$ samples were analysed with a PANalytical $\mathrm{X}^{\prime}$ Pert Pro $^{\mathrm{TM}}$ powder diffractometer with $\mathrm{X}^{\prime}$ Celerator detector and variable divergence- and receiving slits with Fe-filtered Co-K alpha radiation. The sample stage was an Anton-Paar ${ }^{\mathrm{TM}}$ HTK16 furnace using a Pt-heating filament. The sample was scanned at $25^{\circ} \mathrm{C}$, then heated to $1000^{\circ} \mathrm{C}$, scanned, and then heated to $1500^{\circ} \mathrm{C}$ in steps of $100^{\circ} \mathrm{C}$ and scanned at each interval. The phases were identified using X'Pert Highscore ${ }^{\mathrm{TM}}$ plus software. Due to the slight oxidation effect when increasing the temperature, the measurement was repeated in nitrogen atmosphere. The measurement was carried out on the foil, but - in order to detect all reflections - the measurement was repeated on fine Rh powder. 
Rhodium foil and granulates (20 mesh) were used for the DTA measurements. Heating and cooling of the sample was programmed using a TA Q600 STA instrument with a horizontal balance and furnace configuration. An inert experimental atmosphere of nitrogen at a purge rate of $100 \mathrm{sccm}$ was implemented. Standard calibration procedures were used as described for the instrument in the temperature range from 1000 to $1450^{\circ} \mathrm{C}$ at a heating rate of $10{ }^{\circ} \mathrm{C} / \mathrm{min}$. Inert alumina crucibles were used for both sample and reference pans to avoid any interactions of the metal sample with the sample pans. Temperature calibration was performed, using the melting point of gold $\left(\mathrm{Tm}=1083.4^{\circ} \mathrm{C}\right)$

\section{ACKNOWLEDGEMENTS}

The authors wish to thank B Bokarov from Khlopin Radium Institute, Saint Petersburg, Russia, and C. Basu from Saha Institute of Nuclear Physics, Kolkata, India for their help in the interpretation of the physical-chemical background of our results. The authors also thank Necsa for permission to publish this work.

\section{References}

1 van Rooyen J, Szucs Z, Zeevaart JR (2008) Applied Radiation and Isotopes, 66:13461349

2 Aleksejev E, Radiokhimiya (2003) 45: 385-411

3 Aleksejev E, Bondarevskij S I, Eremin VV, Radiokhimiya (1998) 40:427-443

4 Gmelins Handbuch (1935) Rhodium 64:14-20

5 Szucs Z, Steyn D, Vermeulen E, Van der Walt IJ, Moodley K, Verryn S, Zeevaart JR , 7th International Conference on Nuclear and Radiochemistry, Budapest, Hungary 24-29 August 2008, abstract book 240

6 Savitskii EM(Editor) (1990), Handbook of Precious Metals ISBN-10: 0891167099

7. SavitskiiEM, Physical Metallurgy of Platinum Metals

8 Kaye and Laby, Tables of Physical and Chemical Constants , 14 Ed, 9 Engelhard Technical Bulletin (1965) VI, 3,.

10 BaleES(1958) The structure of Rhodium, Platinum Metals, Rev. 2, (2): 61 - 63 
11 Darling AS (1963) Properties of Rhodium at high temperatures, Platinum Metals, Rev., , 7, (4): 144 - 146.

12 Arblaster JW,(1997) Crystallographic Properties of Rhodium, Platinum Metals Rev., , 41, (4): $184-189$.

13 BrownME (1988). Introduction to Thermal Analysis, Techniques and Applications, London, Chapman and Hall

14 Wendlandt WWM (1986) Thermal Analysis, third edition ISBN 0-471-88477-4, 